\title{
Aetiology of peptic ulcer: a prospective population study in Norway
}

\author{
Roar Johnsen, Olav Helge Førde, Bjørn Straume, Per G Burhol
}

\begin{abstract}
Study objective - To analyse simultaneously the effect of several risk factors for peptic ulcer.

Design - Cohort study where all patients with new or incident peptic ulcers in a well defined population were registered for a seven year period. The follow up started with a comprehensive health survey including a questionnaire on diet, lifestyle, psychological and social conditions, and health. Relative risks, both sex specific and separate, for gastric and duodenal ulcers were estimated from proportional hazard regression analysis. Setting - A population based survey conducted in the municipality of Tromsø, northern Norway.
\end{abstract}

Participants - In 1980, a total of 21440 men and women, aged 20 to 54 years and 20 to 49 years respectively, were invited to participate. A total of 14667 people attended and returned the questionnaire. Main results - A total of 328 people had their first peptic ulcer in the follow up period. Age, cigarette smoking, first degree relatives with peptic ulcer, and low educational level were shared risk factors for peptic ulcer in both men and women. In men, frequent upper respiratory infections increased the risk of gastric ulcer and drinking a great deal of milk increased the risk of duodenal ulcer. None of the other dietary variables, including coffee and alcohol consumption, contributed significantly to the risk. Use of analgesics was not a risk factor, and none of the psychological indicators analysed carried any significant risk.

Conclusions - Age, inheritance, and cigarette smoking are all important risk factors for peptic ulcer. The increased risk associated with low educational background indicate that social strains, comprising lifestyle and diet habits, are part of the multifactorial aetiology of peptic ulcer. No support was found for the assumption that peptic ulcer disease is a psychosomatic disorder. This study did not support the view that duodenal and gastric ulcers have different aetiologies - rather it showed a similarity in risk patterns.

\section{( $(\mathcal{F}$ Epidemiol Community Health 1994;48:156-160)}

The aetiology of peptic ulcer disease is still dubious. There is controversy about the possible effect of stress, ${ }^{1-4}$ inheritance, ${ }^{5-7}$ cigarette smoking, ${ }^{8}$ and use of analgesics, ${ }^{9-10}$ as well as social conditions and personal traits, psychological factors, and diet. ${ }^{11-12}$ Even the assertion that the risk in men and women is different is questioned. ${ }^{13-14}$ Divergent views persist on whether duodenal and gastric ulcer are the same disease with different localisation or separate disease entities. ${ }^{15-16}$

Helicobacter pylori has recently been introduced as the aetiologic agent in peptic ulcer disease, ${ }^{17}$ but several studies have shown that it is also present in 30 to $50 \%$ of people without dyspepsia, ${ }^{17-19}$ indicating that its role may not be so important. Carefully designed studies of other risk factors are therefore of great interest.

Most studies of the aetiology of peptic ulcer have been case-control studies of hospital patients ${ }^{9-10}$ or cross sectional surveys of general populations. ${ }^{12}$ Traditionally, an apparent ulcer has been required for the diagnosis of peptic ulcer disease. This has excluded a number of people with the disease and has resulted in biased samples. We are not aware of any cohort study in which several possible risk factors were determined at the start of the study..$^{20}$ Such studies that offer the possibility of analysing the effects of several putative risk factors simultaneously in well defined cohorts of sufficient size are needed. ${ }^{11}$

This cohort study aimed to explore the aetiology of peptic ulcer disease in a prospective study in which information on history of disease and health indicators, diet, lifestyle, social, and psychological factors were available from the cross sectional study.

Subjects and methods

In a comprehensive health survey in the municipality of Tromsø in 1979-80, ${ }^{21}$ all men born between 1925 and 1959 and all women born between 1930 and 1959 were invited to participate. A total of 21440 were eligible. Altogether 16621 people attended and 14667 returned a supplementary questionnaire that included several items on health and lifestyle, and questions on dyspeptic symptoms and peptic ulcer occurrence.

The University Hospital in Tromsø is the only hospital in the area. There are no private doctors, institutes, or other hospitals with the required diagnostic facilities in the area (the distance to the nearest alternative hospital is $250 \mathrm{~km}$ ). All $x$ ray examinations, upper gastrointestinal endoscopies, and actual operations performed on the study population between 1979 and 1987, were reviewed for peptic ulcers. To ensure that all registered ulcers were "new" or "incident", the medical 
records of all cases were examined. Those who reported at the screening in 1979/80 that they had had a peptic ulcer and whose claim could be verified through medical records, were excluded from the study population.

The diagnostic criteria for peptic ulcer diagnosed by $x$ ray examinations or by endoscopy, and the censoring for death and migration, were as follows. All $x$ ray examinations had to be performed with the double contrast method; an ulcer seen on $x$ ray was considered to be gastric or duodenal depending on which side of a dividing line $3 \mathrm{~cm}$ proximal to the pylorus the lesion was seen. With regard to endoscopy, gastric or duodenal ulceration was diagnosed where a crater of at least $0.5 \mathrm{~cm}$ could be seen proximal or distal to the pylorus respectively. Only one ulcer episode was recorded in each subject, except when ulcers at different locations were diagnosed at different times. When the total number of peptic ulcers is given, however, this corresponds with the number of subjects with new peptic ulcers. The population at risk was censored for all deaths recorded by the Central Bureau of Statistics of Norway during the period. Altogether 237 men and 67 women died during the study period. The bureau also provided information on individual migration in the study population (2234 men and 2099 women) but not on the exact time of leaving. As an approximation for censoring purposes, all migration was recorded as taking place in the middle of the follow up period - that is, 3.5 years were used as the mean observation time for these people. ${ }^{22}$

The following independent variables were introduced in the regression analyses:

(1) Sociodemographic characteristics - age (in years); sex; ethnic origin (Norwegian, Finnish, Lapp); change in residence last year; unemployment last year; shift work, night work (all yes/no answers); length of education $(<8,8-10,11-12,>13$ years).

(2) Family characteristics - living conditions during childhood (graded in four categories); full time housewife occupation; occurrence of peptic ulcer in first degree relatives (all yes/no answers).

(3) Lifestyle indicators - body mass index (weight $/$ height $^{2}$ ), systolic and diastolic blood pressure ( $\mathrm{mmHg}$ ); cholesterol, triglycerides and blood glucose concentrations ( $\mathrm{mmol} / \mathrm{l})$; daily cigarette smoking (if yes, how many cigarettes were smoked per day); former cigarette smoking and how many years since smoking was stopped; type of bread most commonly used (white, brown); graded answers (three or four categories) on the use of analgesics (from one to three times a week to rarely or never), consumption of coffee (from never to nine or more cups/day), milk (from never to five or more glasses/day), wine, beer, liqueur (all, from never to about daily), slices of bread (from less than two to 13 or more/day), physical activity at work (from mainly sedentary work to mainly heavy physical work) and leisure (from never to daily), the frequency of alcohol intoxication (from never to about daily), fish as main dish (from less than once a week to five to six times a week), and use of minced meat (from less than once per month up to twice or more a week).

(4) Dimensions of health status - there were yes/no answers on questions concerning sleeping disturbances, diabetes, kidney stones, low back pain, rheumatoid arthritis, hypertensive treatment, frequent upper respiratory tract infections. Mental depression, problems of coping, and insomnia were determined (from not at all to much more than usual).

Only subjects with a complete set of variables were included in the study.

\section{STATISTICS}

The association between peptic ulcers and other variables was analysed by Cox regression models. ${ }^{23}$ The applied statistical programme tests if the proportional hazard assumption is satisfied. ${ }^{23}$ Only variables that contribute significantly $(p<0.05)$ to the explained variance in separate regressions for any of the peptic ulcer locations, in either men or women, were included in the final regression model. Absolute risk calculations (incidences) were age adjusted by direct standardisation with the total study population as a reference. The population attributable risk was estimated according to Lilienfeld. ${ }^{24}$

Relative risk (RR) was calculated from the regression coefficients (beta) as an antilog of beta, and corresponding confidence intervals as an antilog of beta $\pm 1.96 \times$ SE. $^{25}$

Testing for interaction was performed by adding product variables in the regressions.

\section{Results}

A total of 328 subjects with incident ulcers were registered among the 21440 in the study population during the follow up period. The Cox's proportional hazards analysis included 13528 subjects without peptic ulcer and 243 with incident peptic ulcer who had given complete answers in the supplementary questionnaire in 1979-80.

Age adjusted absolute risks, given as incidences per 1000 person/years during the follow up period, are shown in table 1. Daily smoking, low educational level, and having first degree relatives with peptic ulcer showed the highest absolute risks. The population attributable risks of daily cigarette smoking were $53 \%$ and $60 \%$ for gastric and duodenal ulcer, respectively. The corresponding risk of heavy milk drinking was $27 \%$ for duodenal ulcer for both sexes, and $39 \%$ in men only.

The relative risks shown in tables 2-5 were estimated from the final Cox regression analysis in which the variables were included simultaneously.

The risks from the separate analyses of gastric and duodenal ulcers are shown in table 2. Age (the RR for each year and the RRs for ages 30 and 49 years compared with age 20 years, respectively); cigarette smoking; and having relatives with peptic ulcer disease were significant risk factors for both ulcer locations, although their relative strength differed to 
Table 1 The number of peptic ulcers (No), the age adjusted incidences $(I)^{*}$ per 1000 person years, and the relative risks $(R R)$ during the seven years follow up in 13771 men and women for some risk factors. Tromso 1979-87.

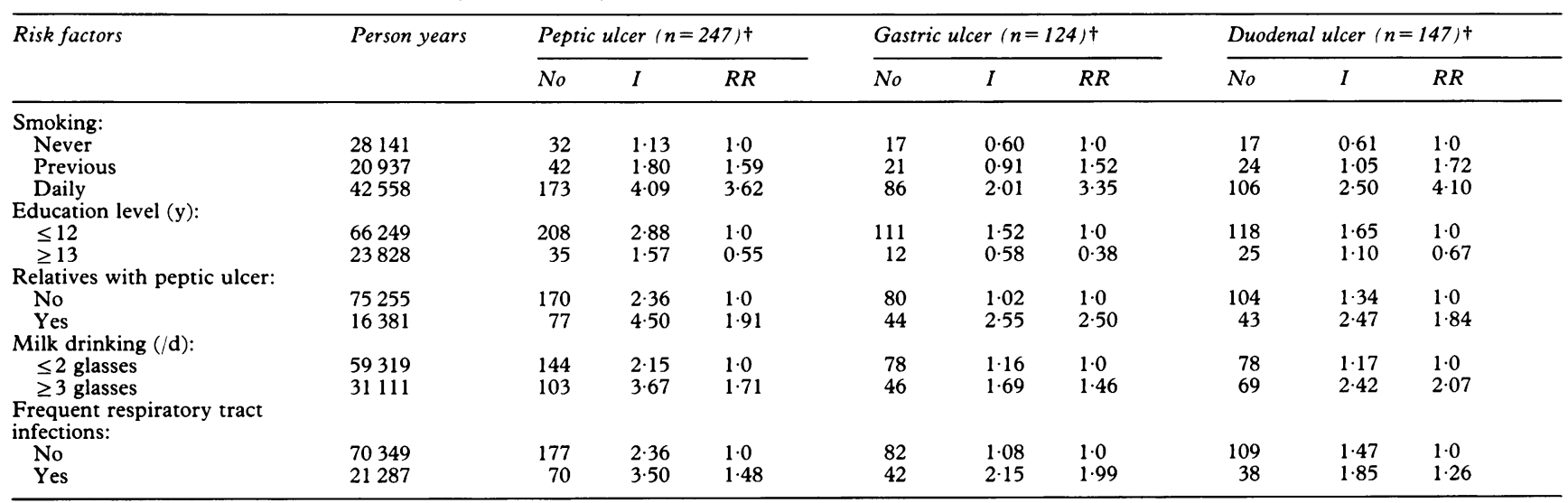

* Age adjusted by direct standardisation.

† The number of ulcers varies due to missing answers.

Table 2 The relative risks ( $R R$ ) (95\% confidence intervals (CI)) for variables significantly contributing to predicting peptic ulcer in a proportional hazard general linear model in 13771 men and women, censored for annual death and average migration. Tromso 1979-87.

\begin{tabular}{|c|c|c|c|}
\hline Predictors & $\begin{array}{l}\text { Peptic ulcer }(n=243) \\
R R(95 \% C I)\end{array}$ & $\begin{array}{l}\text { Gastric ulcer }(n=123)^{*} \\
R R(95 \% C I)\end{array}$ & $\begin{array}{l}\text { Duodenal ulcer }(n=143)^{*} \\
R R(95 \% C I)\end{array}$ \\
\hline $\operatorname{Age}(/ y)$ & $1.06(1.04,1.07)$ & $1.08(1.06,1 \cdot 10)$ & $1.04(1.03,1.07)$ \\
\hline $30 v 20 \mathrm{y}^{\dagger}$ & $1.76(1.51,2.05)$ & $2 \cdot 14(1.72,2.67)$ & $1.55(1.28,1.88)$ \\
\hline $49 v 20 \mathrm{y}^{\dagger}$ & $5 \cdot 14(3.32,7 \cdot 96)$ & $9 \cdot 11(4 \cdot 81,17 \cdot 2)$ & $3.58(2.05,6.24)$ \\
\hline Sex (male $v$ female) & $1 \cdot 62(1 \cdot 21,2 \cdot 16)$ & $1.36(0.91,2.03)$ & $1.93(1.31,2.85)$ \\
\hline Length of education (/category of 4 ) & $0.78(0.67,0.91)$ & $0.72(0.57,0.91)$ & $0.84(0.69,1.02)$ \\
\hline$>14 v<8$ years of education $t$ & $0.48(0.30,0.76)$ & $0.38(0.19,0.77)$ & \\
\hline $\begin{array}{l}\text { Ulcer in } 1 \text { st degree relatives } \\
(0=\text { no, } 1=\text { yes })\end{array}$ & $2 \cdot 14(1 \cdot 63,2 \cdot 81)$ & $2.53(1.74,3.66)$ & $1 \cdot 96(1 \cdot 37,2 \cdot 81)$ \\
\hline $\begin{array}{l}\text { Cigarette smoking } \\
(0=\text { no, } 1=\text { yes })\end{array}$ & $2 \cdot 47(1 \cdot 87,3 \cdot 26)$ & $2 \cdot 40(1.62,3 \cdot 54)$ & $2 \cdot 71(1 \cdot 87,3 \cdot 92)$ \\
\hline $\begin{array}{l}(0=\text { no, } 1=\text { yes }) \\
\text { Glasses of milk (/category of } 4)\end{array}$ & $1 \cdot 23(1.05,1.44)$ & $1.14(0.91,1.42)$ & $1.31(1.07,1.61)$ \\
\hline$>4 v 0$ glasses $/ \mathrm{d} \dagger$ & $1.86(1.16,2.99)$ & - & $2.24(1.21,4.14)$ \\
\hline $\begin{array}{l}\text { Upper respiratory tract infections } \\
(0=\text { no, } 1=\text { yes })\end{array}$ & $1.36(1.03,1.80)$ & $1 \cdot 86(1 \cdot 27,2 \cdot 70)$ & $1 \cdot 16(0 \cdot 79,1 \cdot 68)$ \\
\hline
\end{tabular}

* Combined ulcers are included in both locations.

+ Computed comparisons.

Table 3 The relative risks ( $R R$ ) (95\% confidence intervals (CI)) for variables significantly contributing to predicting peptic ulcer in a proportional hazard general linear model in 6864 men, censored for annual death and average migration. Tromso 1979-87.

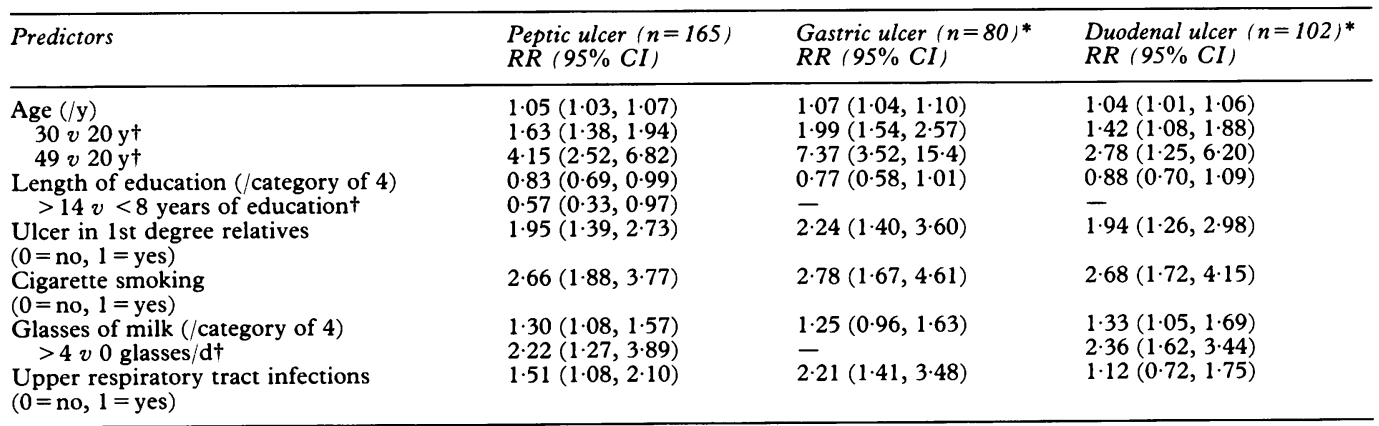

* Combined ulcers are included in both locations.

† Computed comparisons.

Table 4 The relative risks ( $R R$ ) (95\% confidence intervals (CI)) for variables significantly contributing to predicting peptic ulcer in a proportional hazard general linear model in 6907 women, censored for annual death and average migration. Tromso 1979-87.

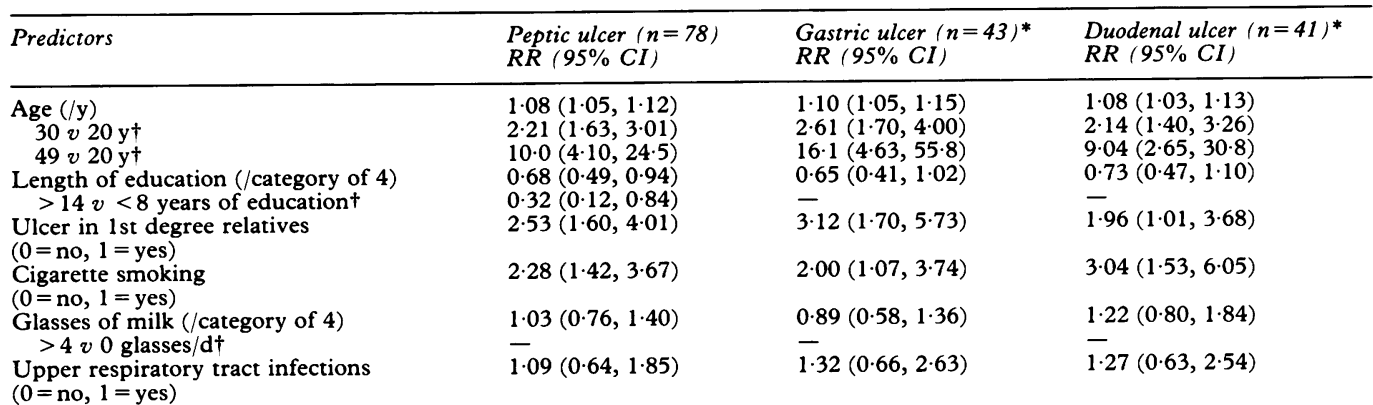

* Combined ulcers are included in both locations.

+ Computed comparisons. 
Table 5 The relative risks ( $R R$ ) (95\% confidence intervals (CI)) for variables significantly contributing to predicting peptic ulcer in a proportional hazard general linear model in 11159 men and women without dyspeptic symptoms in 1979, censored for annual death and average migration. Tromso 1979-87.

\begin{tabular}{|c|c|c|c|}
\hline Predictors & $\begin{array}{l}\text { Peptic ulcer }(n=125) \\
R R(95 \% \text { CI })\end{array}$ & $\begin{array}{l}\text { Gastric ulcer }(n=64) * \\
R R(95 \% C I)\end{array}$ & $\begin{array}{l}\text { Duodenal ulcer }(n=71)^{*} \\
R R(95 \% C I)\end{array}$ \\
\hline Age $(y)$ & $1.06(1.04,1.09)$ & $1.09(1.05,1.12)$ & $1.05(1.02,1.08)$ \\
\hline $30 v 20 \mathrm{y}^{\dagger}$ & $1.84(1.49,2.28)$ & $2.30(1.68,3.16)$ & $1.60(1.22,2.11)$ \\
\hline $49 v 20 \mathrm{y}^{\dagger}$ & $5.86(3 \cdot 16,10 \cdot 9)$ & $11 \cdot 2(4 \cdot 49,28 \cdot 0)$ & $3.94(1.84,8.95)$ \\
\hline Sex (male $v$ female) & $1 \cdot 16(0.79,1.72)$ & $0.75(0.44,1.29)$ & $1 \cdot 81(1.05,3 \cdot 14)$ \\
\hline Length of education ( category of 4 ) & $0.81(0.66,1.00)$ & $0.72(0.52,0.99)$ & $0.92(0.71,1.19)$ \\
\hline$>14 v<8$ years of education ${ }^{\dagger}$ & $0.53(0.28,0.99)$ & $0.37(0.14,0.98)$ & - \\
\hline $\begin{array}{l}\text { Ulcer in } 1 \text { st degree relatives } \\
(0=\text { no, } 1=\text { yes })\end{array}$ & $2.09(1.47,3.07)$ & $3 \cdot 18(1.93,5 \cdot 26)$ & $1.45(0.83,2.53)$ \\
\hline $\begin{array}{l}\text { Cigarette smoking } \\
(0=\text { no, } 1=\text { yes })\end{array}$ & $2 \cdot 11(1.45,3 \cdot 06)$ & $2.32(1.37,3.93)$ & $2 \cdot 18(1.32,3.59)$ \\
\hline Glasses of milk (category of 4 ) & $1.24(0.99,1.55)$ & $1.04(0.75,1.43)$ & $1.42(1.06,1.91)$ \\
\hline $\begin{array}{l}>4 \vee 0 \text { glasses } \mathrm{d}^{\dagger} \\
\text { Upper respiratory tract infections } \\
(0=\text { no, } 1=\text { yes })\end{array}$ & $\overline{1.44}(0.97,2 \cdot 13)$ & $\overline{1.78}(1.05,3.04)$ & $\begin{array}{l}2.89(1.19,7.01) \\
1.38(0.82,2.33)\end{array}$ \\
\hline
\end{tabular}

* Combined ulcers are included in both locations.

+ Computed comparisons.

some degree. The main differences were a stronger association with age and a positive family history for gastric ulcer. Smoking conveyed approximately the same risk for both gastric and duodenal ulcer. In separate univariate analyses, no linear relationship was found between the number of cigarettes smoked and risk of peptic ulcer. Besides these three common risk factors, male sex and high milk consumption (compared with never or seldom drinking milk) increased the risk of developing duodenal ulcers, whereas low educational level and reporting frequent upper respiratory tract infections were associated with a greater risk for gastric ulcer.

The results of the sex specific Cox regression analyses are shown in table 3 for men and table 4 for women. Age, cigarette smoking, low educational level, and having relatives with peptic ulcer disease were significant risk factors common to both men and women. The corresponding relative risks were highest for women, but the confidence intervals overlapped. A high milk consumption and frequent upper respiratory infections were associated with an incresed risk of peptic ulcer in men.

Psychological factors such as depression, sleeping disturbances, problems with coping, social indicators of poor living conditions in childhood, and the use of analgesics were tested alone and together in the Cox model with age, sex, cigarette smoking, educational level, and having relatives with ulcer, but no significant association with peptic ulcer was found.

An analysis restricted to those who reported no dyspeptic symptoms before 1979-80 are shown in table 5 . The results were principally the same among the risk factors and with the same mutual strength.

\section{Discussion}

The lack of consistent agreement on the aetiology of peptic ulcer is not merely a result of the shortage of epidemiological studies with a classic prospective design. Inherent requisites for a study are unbiased assessments of both exposure and end points, which are unattainable for peptic ulcer disease. Although the appearance of an ulcer is the most prominent, and probably the only countable event in peptic ulcer disease, it is nevertheless a "soft" end point. Firstly, the prevalence of silent ulcers, the intensity of symptoms, patients' self selection and doctors' decisions considering diagnostic efforts make this an easily biased end point. ${ }^{14}$ Secondly, the fact that an ulcer does not exist or is unrecognisable at the time of examination, does not, of course, exclude the presence of peptic ulcer disease. On the exposure side, the chronic nature of the disease with periodic outbursts of symptoms, may initiate lifestyle changes long before the diagnosis of an ulcer.

Because we are aware that most of these insurmoutable methodological problems lead to uncertainties about possible causal associations, we have carried out a large population based prospective study assessing a broad spectrum of exposure variables. We decided not to use symptom status as a risk factor in the analysis. Instead, we did a separate analysis of subjects who denied having had dyspeptic symptoms before the start of the follow up. The risk pattern in this analysis did not differ from the results of the analysis in the total population.

Age, smoking cigarettes, and having first degree relatives with peptic ulcer were common risk factors for developing both gastric and duodenal ulcers in both sexes, although the size of the relative risks varied somewhat, both with sex and the location of the ulcer. Neither use of analgesics, psychological factors, nor diet were significant risk factors for peptic ulcers in this study.

The inheritance of peptic ulcer is considered heterogenetic with a polygenic basis, and is, among other things, linked to the AB0 system and secretor status. ${ }^{7}$ In this study, the increase in risk of having one or more first degree relatives with peptic ulcer was most marked for gastric ulcer. In a stratified analysis to evaluate the risk pattern in subjects with and without a family history of peptic ulcer, the risk pattern turned out to be about the same in both strata, with only minor and inconsistent differences.

The association between cigarette smoking and peptic ulcer seems well documented. ${ }^{810}$ Although no dose response of cigarettes smoked was observed in this study, it seems beyond doubt that cigarette smoking carries a 
considerable risk for developing both gastric and duodenal ulcer.

All the risk factors, discussed so far, fulfil the criteria for the time sequence of a causal exposure-effect relationship. Somewhat more dubious in this respect is the observed association with milk consumption. The association was independent of whether the milk consumed was whole or skimmed. The explanation closest to hand is that this association reflects the fact that many dyspeptics drink milk to dull the pain. Separate analyses of the symptom free, however, still showed that the relative risk of milk drinking was at least the same size, making the exposure-bias explanation less plausible. It is more likely that milk, through its calcium content, stimulates acid secretion, leading to an association with duodenal ulcer. ${ }^{26}$

Cigarette smoking may be an inherent pathogenetic link to the second of the unexpected risk factors - frequent upper respiratory tract infections. Since frequent upper respiratory infections contribute significantly to the variation in the regression model, other mechanisms explaining the increased risk must be considered. ${ }^{27}$

The lack of association between peptic ulcer and psychological factors was hardly unexpected. ${ }^{7}$ Assumptions about the role of these factors in peptic ulcer disease display an impressive disregard for the lack of evidence in both lay and medically educated people. The status of psychological factors relies mainly on open case-control studies ${ }^{342829}$ with insufficient control for other factors. ${ }^{4829}$ Our findings are consistent with an earlier cross sectional study from Tromsø, where the same psychological variables, extracted from the General Health Questionnaire, ${ }^{30}$ showed a negative association with peptic ulcer but a positive one with non-ulcer dyspepsia ${ }^{12}$ and irritable bowel syndrome. ${ }^{31}$ This weighs against lack of validity in our psychological variables as an explanation for our negative finding.

Low socioeconomic status is a generally accepted risk factor as an indicator of job roles and living conditions. Low socioeconomic status, assessed in this study by years at school, probably represents a sum of strains from lifestyle, diet, and daily social stress. ${ }^{32}$ Since educational level cannot be considered an aetiological factor of its own, a continued search for indicators depicting the specific risk factors inherent in social status, diet included, is needed.

In conclusion, this prospective population study has documented that in both sexes the occurrence of gastric and duodenal ulcer is related to age, inheritance, and cigarette smoking. We were unable to support theories that peptic ulcer is a psychosomatic disorder. The association with milk consumption and upper respiratory infection must be interpreted with caution, in view of the number of factors tested. The changing, and partly contrasting, epidemiology of gastric and duodenal ulcer over time may indicate a different aetiology of the two conditions. The present study, however, shows similarities in the risk pattern rather than differences, and does not support the view that gastric and duodenal ulcers are diseases with different aetiologies.

This study was done in cooperation with the National Health Screening Service, Oslo.

1 Susser M, Stein Z. Civilisation and peptic ulcer. Lancet 1962;i:115-9.

2 Sonnenberg A. Causative factors in the etiology of peptic ulcer disease become effective before the age of 15 years. fournal of Chronic Disease 1987;40:193-202.

3 Piper DW, McIntosh JH, Ariotti DE, Calogiuri JW, Brown $\mathrm{RW}$, Shy CM. Life events and chronic duodenal ulcer: case-control study. Gut 1981;22:1011-7.

4 Tennant C, Gouldston K, Langeluddecke P. Psychological correlates of gastric and duodenal ulcer disease. Psychol Med 1986;16:365-71.

5 Doll R, Buch J. Hereditary factors in peptic ulcer. Annals of Eugenics 1959;15:135-46.

6 Eberhard G. Peptic ulcer in twins. A study in personality, heredity and environment. Acta Psychiatr Scand 1968;44(suppl 205):55-9.

7 Ellis A. The genetics of peptic ulcer. Scand 7 Gastroenterol 1985;20(suppl 110):25-7.

$8 \mathrm{McCarthy}$ DM. Smoking and ulcers - time to quit. $\mathrm{N} \mathrm{Engl} \mathrm{f}$ Med 1984;311:726-7.

9 Piper DW, McIntosh JH, Ariotti DE, Fenton BH, MacLennan R. Analgesic ingestion and chronic peptic ulcer. Gastroenterology 1981;80:427-32.

10 Piper DW, Nasiry R, McIntosh J, Shy CM, Pierce J, Byth $\mathrm{K}$. Smoking, alcohol, analgesics, and chronic duodena ulcer. A controlled study of habits before first symptoms and before diagnosis. Scand $f$ Gastroentero 1984;19:1015-21.

1 Sturdevant RAL. Epidemiology of peptic ulcer. Report of conference. Am F Epidemiol 1976;104:9-14.

12 Johnsen R, Straume B, Førde OH. Peptic ulcer and nonulcer dyspepsia - a disease and a disorder. Scand $\mathcal{F}$ Prim Health Care 1988;6:239-43.

$13 \mathrm{Kurata} \mathrm{JH}$, Haile $\mathrm{MH}$, Elashoff JD. Sex differences in peptic ulcer disease. Gastroenterology 1985;88:96-100.

14 Bernersen B, Johnsen R, Straume B, Burhol PG, Jenssen TG, Stakkevold PA. Towards the true prevalence of TG, Stakkevold PA. Towards the

15 Kirk RM. Are gastric and duodenal ulcers separate diseases or do they form a continuum? Dig Dis Sci 1981;26:149-54.

6 Rotter JI. Gastric and duodenal ulcer are each many dif ferent diseases. Dig Dis Sci 1981;26:154-60.

7 Rauws EAJ, Langenberg W, Houthoff $\mathrm{HJ}$, Zanen $\mathrm{HC}$ Tytgat GNJ. Campylobacter pyloridis-associated chronic active antral gastritis. Gastroenterology 1988;94:33-40.

18 Dooley CP, Cohen H, Fitzgibbons PL, et al. Prevalence of Helicobacter pylori infection and histologic gastritis in asymptomatic persons. N Engl f Med 1989;321:1562-6.

19 Bernersen B, Johnsen R, Bostad L, Straume B, Sommer A I, Burhol PG. Is Helicobacter pylori the cause of dyspepsia? BMJ 1992;304:1276-9.

20 Muller C, Engelke B, Fiedler L, et al. How do clinical results after proximal gastric vagotomy compare with results after proximal gastric vagotomy compare with 1983;7:610-5.

21 Thelle DS, Arnesen E, Førde OH. The Tromsø heart study: does coffee raise serum cholesterol? $N$ Engl f Med 1983;303:1454-7.

22 Johnsen R, Straume B, Forde OH, Burhol PG. Changing incidence of peptic ulcer - facts or artefacts? A cohort study from Tromsø. $\mathcal{f}$ Epidemiol Community Health 1992;46:433-6.

23 SAS Institutes Inc. SUGI supplemental library user's guide. Version 5th ed. Cary, NC: SAS Institute Inc, 1986

24 Lilienfeld AM, Lilienfeld DE. Foundations of epidemiology. New York: Oxford University Press, 1980.

25 Matthews DE, Farewll VT. Using and understanding medical statistics. Basel: Karger AG, 1988.

26 Ippoliti AF, Maxwell V, Isenberg JJ. The effect of various forms of milk on gastric-acid secretion. Ann Intern Med forms of milk

27 Kaufmann F. ABH non-secretor status, blood group 0, and chronic airflow limitation. Lancet 1982;i:513-4.

28 McIntosh JH, Nasiry RW, Frydman M, Waller SL, Piper DW. The personality pattern of patients with chronic DW. The personality pattern of patients with chronic peptic ulcer. A case

29 Piper DW, McIntosh JH, Greig M, Shy CM. Environmental factors and chronic gastric ulcer. Scand $\mathcal{f}$ Gastroenterol 1982;17:721-9.

30 Hansen V, Jacobsen BK. Mental distress and social conditions and lifestyle in northern Norway. $B M F$ 1989;299:85-8

31 Johnsen R, Jacobsen BK, Førde OH. Associations between symptoms of irritable colon and psychological and social conditions and lifestyle. $B M \mathcal{F}$ 1986;292:1633-5.

32 Jacobsen BK, Thelle DS. The Tromsø heart study: risk factors for coronary heart disease and length of education. Am F Epidemiol 1988;16:101-4. 